Article

\title{
Coexistence with Bears in Romania: A Local Community Perspective
}

\author{
Petru Tudor Stăncioiu ${ }^{1, *}$, Ioan Dutcă ${ }^{1,2}{ }^{\infty}$, Marian Cristian Bălăcescu ${ }^{1}$ and \\ Ștefan Vasile Ungurean ${ }^{3}$ \\ 1 Faculty of Silviculture and Forest Engineering, Transilvania University of Brasov, 500036 Brasov, Romania; \\ idutca@unitbv.ro or Ioan.Dutca@bucks.ac.uk (I.D.); marian.balacescu@unitbv.ro (M.C.B.) \\ 2 Research and Enterprise Development Unit, Buckinghamshire New University, High Wycombe HP11 2JZ, UK \\ 3 Faculty of Sociology and Communication, Transilvania University of Brasov, 500036 Brasov, Romania; \\ s.ungurean@unitbv.ro \\ * Correspondence: petru.stancioiu@unitbv.ro; Tel.: +40-268-415-406
}

Received: 28 October 2019; Accepted: 12 December 2019; Published: 14 December 2019

\begin{abstract}
In the modern context of the strict protection of large carnivores, the competition for resources between local community dwellers and these animals has become an important challenge for ensuring coexistence-the key for conservation success. To assess the perceptions of this intricate relationship, six local communities from Central Romania, located in areas with high-density brown bear (Ursus arctos L.) population and frequent conflicts, were investigated. A large proportion of the respondents $(69 \%)$ showed various forms of intolerance (e.g., relocation, punishment, or killing) towards aggressive bears. However, the cognitive evaluation score derived from the level of interaction with bears showed a non-significant $(p=0.470)$ segregation by tolerance levels, suggesting that not only the tangible costs (direct damage) but rather the psychological costs of fear, danger, or risk are more important drivers of negative attitudes towards bears. Furthermore, the prevalent experienced emotions towards an inoffensive bear (fear, terror, and hate, which represent $73 \%$ ) underline the general preference for living in "separate worlds". This requires that bears should avoid humans and their settlements, a goal unlikely to be achieved under the current strict protection regime. Therefore, an alternative strategy that ensures mutual avoidance of the two players may be more appropriate for successful human-bear coexistence.
\end{abstract}

Keywords: competition; bear conservation; human-wildlife conflict; Romania; sustainable management; Ursus arctos

\section{Introduction}

One of the most important interactions inside natural ecosystems which affects the amount of available vital resources (i.e., the "habitat" [1] or the "growing space" [2]) for a certain individual or species is competition. This fight for the same resources can be fierce and generally brings conflict between different species, which must be carefully managed in order to ensure the coexistence of both players. Nowadays, the coexistence between wild animals and humans has become very important especially in the modern context of large carnivore conservation. However, the long-term viability of large carnivore populations in shared landscapes cannot be achieved without the tolerance of human communities [3]. In the parts of Europe where carnivores are still present, proving that coexistence is possible- these species became strictly protected so they cannot be controlled anymore through sustainable hunting, to prevent the conflict. As a result, the conflict is a side effect of conservation itself and coexistence might be affected.

As some species like bears can also pose a threat to human life, the conflict triggers intense emotions but sometimes very contradicting perceptions in modern society. The human behavior 
is driven by specific attitudes or emotions $[4,5]$ and therefore, the analysis of the conflict context must include the attitudes of humans towards wildlife [6] and also the drivers which are changing these attitudes in time. However, emotions vary greatly among people who are subject to different experiences with a certain animal species $[7,8]$. Although all three categories of emotions (positive, neutral, and negative) could be encountered, the policymaking process is frequently shaped by the extremes (i.e., positive vs. negative).

In the past, large carnivores became rare and even extinct in some parts of Europe, being persecuted either because they brought fear [9] or because they were considered a nuisance [10]. Despite the existing knowledge and past experience which have led to extinction in some areas or sustainable management and increase/recovery of carnivore populations in others, different social groups still have different opinions on such issues. The potential for conflict, therefore, hinders the selection of appropriate tools and actions for conservation in the areas where such species are still present. The relatively recent changes in national legislation (due to the European Union (EU) accession) in countries with vigorous populations of bears, such as Romania and Croatia, could suggest that the modern concept of carnivore conservation through strict protection, which replaced the active management through sustainable hunting, is a generally accepted and successful tool in such particular situations as well. The rejection of this protection regime seems to be the choice of a very small minority, including people who are living in direct contact and/or had direct conflicts with these animals and hunters who regard these species as a commodity.

The particular case of Romania, where brown bears (Ursus arctos L.) and humans have shared and still share the same natural landscapes for millennia without a relatively sharp boundary between their habitats like in other regions of the world [11,12], could provide useful information for the conservation through coexistence of the two players (i.e., humans and bears) and could help conservation in other countries as well. Here, small farming and shepherding along with forest management are still employed across natural landscapes in a very intricate mosaic of forests, orchards, agricultural lands, grasslands and other types of land cover. Such areas, many times "in the backyard", are used by bears for foraging. Compared to other carnivores like lynx and wolf, these powerful carnivores do not always fear humans, and, thus, they use rural and urban areas for food and sometimes even aggress people. Despite the large numbers of bears (around 6000, [13]), the stability of the population and the fact that active management ensured its conservation in the past and an almost tenfold increase after World War II [13], the species became strictly protected after being classified as threatened at the time of accession into the EU in 2007. Such an abrupt change in the management of bears could affect the existing relatively peaceful coexistence of the two players.

Another particular aspect is that the bear population is concentrated mostly around the Carpathian Mountains, in areas with smaller and less dense human communities (mostly villages and smaller towns), which represent a small share of the total population of the country. The two community types (inside and outside bear habitats) are expected to think differently: human dwellers still living within natural landscapes, experiencing direct contact with the wildlife and still having safety and subsistence needs, show more negative feelings [8] and have a more domination attitude (prioritizing human well-being over wildlife, rooted in safety and subsistence needs [4]) while those living far from the ecosystem tend to show mutualism (i.e., egalitarian ideology in human-wildlife relationship with wildlife, being considered capable of a relationship of trust with humans, and, thus, deserving similar rights and also caring [4]) with the animals. Therefore, attitudes and perceptions about bears could vary largely across Romania, a country hosting one of the largest populations of bears in Europe [13]. Moreover, the overall decision-making may be heavily imbalanced towards the more numerous people (urban or rural dwellers) living outside of a particular area or ecosystem (i.e., people not part of the population in ecological terms) and the particular perceptions of some smaller local communities living inside the ecosystem could be masked.

Additionally, the relatively recent policy changes, which completely restricted any active management that has been keeping bear density under control through sustainable hunting, has 
produced an increase in bear density inside their former habitat area and also expansion into new areas. Moreover, banning of lethal control based management has also caused a reduction in what is called "the landscape of fear" [14] where animals avoid areas with higher risks of predation $[15,16]$ and, thus, has favored more frequent conflicts with humans (damage on goods or attacks on people). Therefore, passive management seems to increase both the direct tangible costs (direct damage affecting some dwellers) and the intangible costs associated with wildlife (such as fear, danger, or risk affecting a greater number of dwellers). As the latter category was shown to be more important in driving human attitudes [17], these relatively recent policy changes could bring intolerance towards bears in the local communities, hindering conservation efforts on the ground instead of supporting them. However, human tolerance is needed for the maintenance of carnivore populations in shared natural landscapes [3]. Therefore, learning more about human tolerance to carnivores in this new context would be one of the key actions for ensuring the long-term persistence of large carnivores inside the natural landscapes they share with people. The present study aims to analyze the perceptions of dwellers from local communities embedded in the bear habitat landscapes (where the presence of these carnivores and conflicts are quite common) based on their direct and indirect interaction with the animals now placed under strict protection. These communities play an important role in successful conservation on the ground, being a very powerful competitor for carnivores; a competitor directly influencing their survival [18]. The relatively recent imposed strict protection of carnivores creates a new, very particular and interesting context for research: landscapes with both players (and especially high densities of large carnivores), but with human competitive abilities completely alienated while bear competitive abilities are not controlled anymore. Such a situation would generally lead to exclusion rather than cohabitation [18]. However, despite the fact that bears seem to have all competitive abilities over humans at present, animals and not the local dwellers would more likely be excluded, as has already happened in other parts of the world for the reasons mentioned above $[9,10]$. As coexistence is the key to maintain such carnivores in the natural landscapes, and coexistence requires tolerance, it is important to investigate how this competition evolves under the recently imposed strict protection regime.

Identifying the particular aspects which favor or threaten the coexistence of large carnivores with people from these communities can be used to maintain the large and viable carnivore populations in the Romanian Carpathians and could also be useful in other countries as well to ensure persistence or recovery of carnivore populations. Therefore, it is important to determine whether local dwellers generally favor the present protection regime (i.e., having a more mutualistic approach based on trust and tolerance) or are against it (i.e., having a domination approach based on fear and rejection or subsistence needs) $[4,7,8]$. The following hypothesis is tested: the more a person accumulates negative experiences with the bear, the more the person's own interests will prevail over the public common interests (i.e., the protection of the bear in this case). As a result, only when the experience intensity is increasing, the intolerance will also increase, evolving towards extreme forms (solutions). If this is confirmed, dwellers of local communities will show the same segregation of attitudes (those incurring less or no damage will show more positive attitudes; those incurring direct conflict will show more negative attitudes) as found in other studies carried out at much larger scales on the general public $[4,7,8]$. However, if such segregation is not present, the overall perceptions of these local communities could be used as a key for successful conservation on the ground.

\section{Materials and Methods}

\subsection{Study Area}

Romania, located in the Eastern part of Europe, has a temperate climate and various landforms ranging from the sands of the Black Sea coast and the wetlands of the Danube Delta to the steep slopes and heights of the Carpathian Mountains. Altitudes range from sea level to $2500 \mathrm{~m}$. The climate is temperate continental with wet summers and cold winters. These diverse site conditions promote 
a diverse vegetation cover which offers habitat to a rich wildlife fauna. The forests, concentrated mostly around the Carpathians, range from oaks (Quercus robur L., Q. petraea (Matt.) Liebl. and others) dominated stands in the lowlands to European beech (Fagus sylvatica L.) stands in the mountainous regions and the pure Norway spruce (Picea abies (L.) Karst.) in the higher altitudes up to the tree line. This forested landscape, which covers roughly 6.9 million ha [19] (29\% of the country area) harbors the largest population of brown bears in Europe (except for Russia) [13]. This population has coexisted with the people embedded in the natural landscapes for ages and, in the last century, increased almost tenfold under active management (which included rigorous control of poaching but also sustainable hunting as a measure to keep optimal population densities). Game management is strictly regulated by the state (regardless of land ownership), carried out by professional associations, controlled by state agencies, and aims at maintaining optimal density populations of all species in a game management area. However, populations of strictly protected species are not subject to such management. For brown bears, different conservation strategies were used for a long time. In 1953, when the population reached very low levels $(860$ bears, $[13,20])$ bear hunting was strictly regulated by setting a hunting season and prohibiting the hunting of females with cubs and hunting at dens (Decree 76/1953 [21]). Further, in 1976, the hunting season was reduced to 6 months and split into two periods, spring and fall (Law 26/1976 [22]). Starting in 1996 (Law 103/1996 [23]), bears were declared protected species in Romania. However, up to the accession to the EU (in 2007), population density control through sustainable but strictly regulated and controlled hunting was the main option for conservation in places where densities were higher than normal (Law 103/1996 [23] and Law 407/2006 [24], in its original form). All these legal procedures produced the largest bear populations in Europe. Active sustainable management practiced in the past had some features which deserve to be mentioned: (i) it was planned ahead (with harvests according to a quota approved by the state, not by managers alone) and continuously monitored; (ii) harvests sought to control densities based on the habitat carrying capacity (taking into account population size, sex ratio and age structure) and also to keep conflicts to a low level (by fast and prompt removal of bold individuals). As a result, not only it helped to increase the bear population but also ensured a favorable context for cohabitation of carnivores with humans across large shared natural landscapes.

Under the present passive intervention system (culling only problem animals, without taking into account any of the population parameters and habitat conditions mentioned above), imposed by a political decision at the time of accession to the EU (Government Emergency Ordinance 57/2007 [25]), action is allowed only after bears produce damage or pose a serious threat to humans. The most common solution is relocation. On very rare occasions, animals are culled.

The study was carried out inside the Carpathian range in two small towns (Săcele and Baraolt) and four villages (Cernat, Dalnic, Moacşa, and Băţani) from the central part of the country (Brasov and Covasna counties-Figure 1). The forests cover a great percentage of the land in these areas, harboring large populations of brown bears. Small farming (including extensive grazing) and forestry are the main activities. Interactions between people working the land and bears are common and frequent.

\subsection{Methods}

To analyze the perceptions of the local human populations living inside the same ecosystem with bears and experiencing conflicts, we aim to assess cognition (the perception of an interaction), tolerance (which is defined as "the willingness of a subject to accept a different behavior and different beliefs, even when the subject might not agree with them" [26]) and the experienced emotion of subjects. We used the two-factor theory of emotion [27] according to which an event determines first a physiological reaction (i.e., vegetative activation). Further, to obtain the experienced emotion, the subject must identify a reason for the physiological reaction, or associate this reaction (through cognitive evaluation and labeling) to a certain emotion (anxiety) [27]. We tested the following hypothesis: the more a person accumulates negative experiences with the animal, the more the person's own interests will prevail over public common interests. 


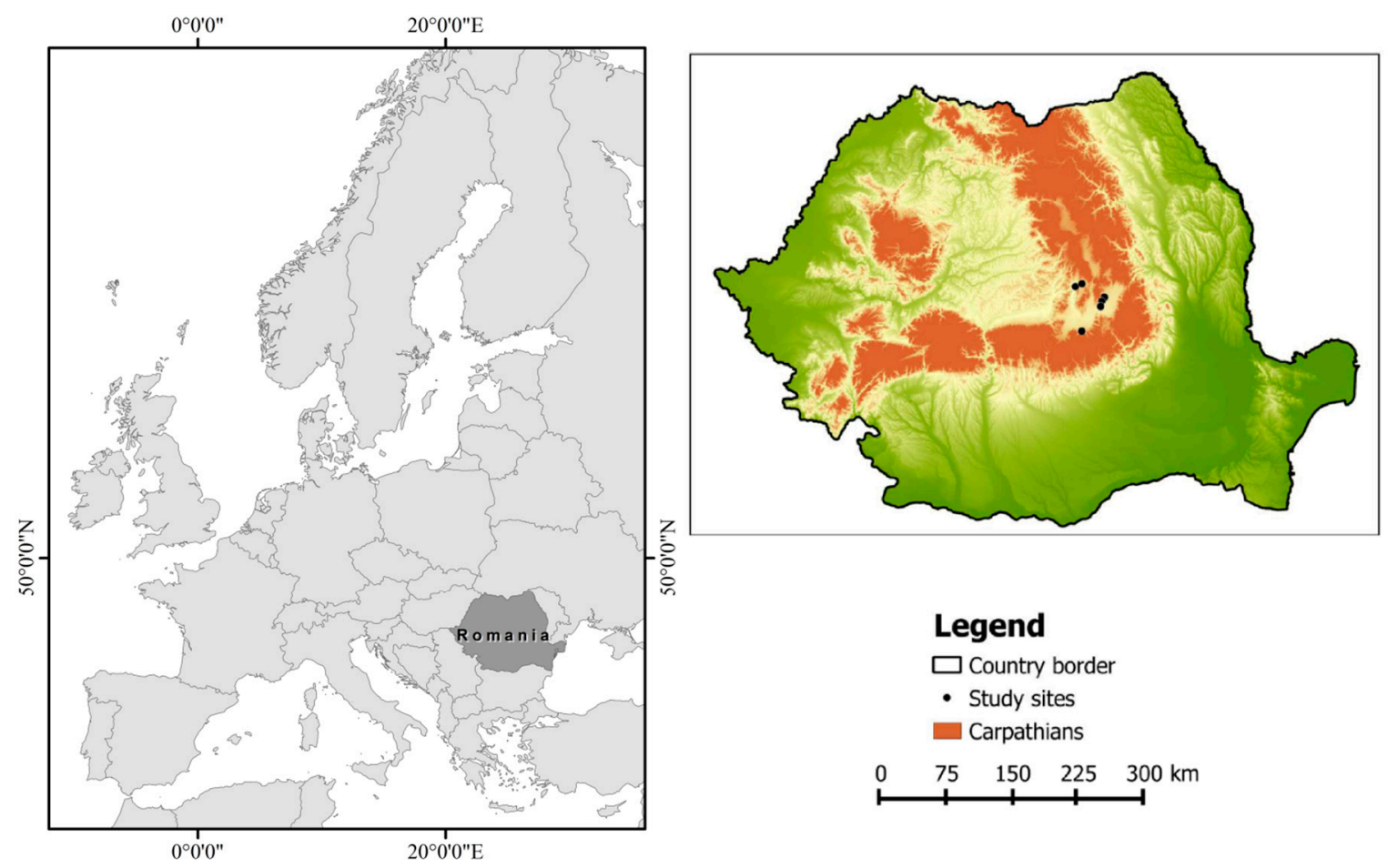

Figure 1. Geographical location of the study area.

To collect anxiety (fear) indices, we used a cognitive evaluation score associated with the events arising from the relationship between the two actors: humans and bears. A questionnaire (Supplementary Material S1) with 8 questions was used for 400 face-to-face interviews carried out in the six local communities targeted by the study. The size of the sample depended on the size of each community. Stratified random sampling was used; the interviewers were instructed to ensure proportional participation of age classes in the communities (18-24 years; 25-34 years; 35-49 years; 50-64 years; over 65 years) and a balanced gender proportion (1:1) (Supplementary Material S2). Interviews were carried out on the street and during the working hours of the day (when most people in these communities are active and chances for encountering most of them are highest). The questionnaire was anonymous, and subjects were informed on this prior to answering the questions. Each subject was informed that: (1) this is a study on opinions related to problems produced by wild animals to people and local communities; (2) the respondent was chosen at random and the information provided by him/her will be used only for statistical purposes. Therefore, each respondent who agreed to participate has expressed his/her free, prior, and informed consent on participation. Also, no personal data (which could be used later for the identification of a particular person) was collected.

The intensity of the human-wildlife relationship as perceived by the human subject was assessed through a series of emotional markers placed in the questionnaire, which gradually focused on: (i) direct experience with the animal (e.g., of the subject or of family members, attack on livestock or crops); (ii) the experience derived from mediated interaction with the animal in the environment of the subject (indirect interpersonal interaction); (iii) the experience derived from a mediated interaction with the animal outside of the environment of the subject (e.g., cases presented in the media, indirect impersonal interaction). Taking into account all these three categories of experience, we tried to cover all possible types of encounters/conflicts with bears. Each category type is given an initial score of 5,3 , and 1 points, respectively. Subsequently, to differentiate between different types of interaction (in terms of emotional intensity level), the score of each category type was weighted (increased).

For direct interaction, we added:

- 8 points if aggression was directed towards the interviewee;

- 6 points if there was aggression towards a person in the interviewee's family; 
- 3 points if a bear entered a household and attacked livestock;

- 2 points if the animal entered a shepherd's camp and attacked the sheep/cows;

- 1 point if planted crops were damaged;

- 0 points if an interviewee declared a lack of experience or did not answer.

The weight to be added to each type of interaction was decided depending on the "distance" of the subject from the threat. This ranged from damage to crops (longest distance to threat-lowest added weight) to a direct attack on the subject (shortest distance to threat-highest added weight). Between these two extremes, added weight increased for damage to livestock (people being more closely attached to their animals than to their agricultural crops) with a higher score if an attack occurred in the household (closer to the subject, trespassing the property) compared to if it happened in a shepherd camp (outside of the village), and finally with a higher score for an attack on relatives (people close to the subject).

For indirect-interpersonal mediated interactions, a score of 3 points was weighted by adding:

- 2 points if the subject had heard that those having the experience "had suffered" (based on the principle of empathy, e.g., "I suffer because others have also suffered");

- 0 points if the subject has not recorded any consequence of the experience (conflict).

For indirect-impersonal mediated interactions, a score of 1 point was weighted by adding:

- 2 points if the subject has heard that those involved in the conflict had suffered;

- 1 point if the subject reports that sometimes people suffered, while at other times they did not;

- 0 points if the subject does not remember if people have suffered.

For each interviewed person, based on direct and/or indirect experience, a cumulated cognitive evaluation score (CES) between 0 and 21 resulted (the score of 21 points resulted from addition of the maximum scores of impersonal mediated, personal mediated and direct interactions since one person could be subject to all types of interaction). The emotional levels of the interaction and the attributed scores are presented in Table 1.

Table 1. Types of interactions with bears, the resulting emotional levels, weights, and scores 1.

\begin{tabular}{|c|c|c|c|c|}
\hline \multicolumn{2}{|l|}{ Interaction Type } & Emotional Intensity Level & $\begin{array}{l}\text { Added } \\
\text { Weight }\end{array}$ & Score \\
\hline \multicolumn{2}{|c|}{ No interaction (initial score 0 ) } & Absent & 0 & 0 \\
\hline \multirow{11}{*}{ With interaction } & impersonal & Absent & 0 & 1 \\
\hline & mediated & Medium & 1 & 2 \\
\hline & (initial score 1 ) & High & 2 & 3 \\
\hline & $\begin{array}{l}\text { personal } \\
\text { mediated }\end{array}$ & Absent & 0 & 3 \\
\hline & (initial score 3) & High & 2 & 5 \\
\hline & direct & Absent & 0 & 5 \\
\hline & (initial score 5) & Low (crops destruction) & 1 & 6 \\
\hline & & Medium (attack on livestock at shepherd camp) & 2 & 7 \\
\hline & & Relatively high (attack on livestock in the household) & 3 & 8 \\
\hline & & High (aggressed relatives) & 6 & 11 \\
\hline & & Very High (aggressed subject) & 8 & 13 \\
\hline
\end{tabular}

${ }^{1}$ Note: For the same subject, it may be reported a maximum score of 13 for direct interaction, plus a maximum score of 5 for personal mediated interaction, and a maximum score of 3 for impersonal mediated interaction, resulting, therefore, in a maximum potential CES value of 21.

Regarding tolerance, the questionnaire has included different action related forms to detect the polarity of tolerance-intolerance. As we aimed to specifically test the perceptions of humans living inside landscapes with bears and experiencing conflict with these powerful carnivores, a priori, the respondent was introduced to a conflict situation ("the bear has aggressed humans, what do you think 
it should be done about it?") to determine a justification of the proposed actions and avoid non-action choices. However, persons inclined to choose no-action could refuse to answer or choose a more friendly option (e.g., option 2 or 5 , see below). Therefore, the alternative answers were

(1) to be tracked down and killed immediately (associated to an extreme intolerance type; exclusion of the one that has a different behavior than the one desired);

(2) to be caught and relocated far away from human settlements (associated to an isolation intolerance type);

(3) to be caught and made to suffer so it would not come back again (associated to an average intolerance type);

(4) to be caught and put in a zoo (associated to an indifference tolerance type);

(5) to be caught and fit with a GPS collar to allow permanent monitoring of his position and presence (associated to a generosity tolerance type).

The analysis also seeks to determine the "experienced emotion" of the subjects. As human actions are driven by motivations and emotions, the latter is important to be determined especially because they have external causes. In an emotional situation, a certain event triggers at the same time the vegetative activation (i.e., physiological reaction) and the cognitive evaluation. The evaluation leads to the perception of this activation and to an opinion (also known as emotional belief) that both trigger the experienced emotion [27].

To detect mostly the cognitive evaluation and not the physiological reaction (vegetative activation), we placed the subjects into a neutral situation: "imagine you encounter in the wild a bear which is not aggressive and does not attack you". Here, "in the wild" meant all areas outside of villages and towns, including those where the habitat of the two is overlapping (prevailing case) and not only the human-devoid areas (in very remote locations, not accessible to humans and no or less used for resource harvesting). We based our analysis on Plutchik's wheel of emotions [28], which shows that primary emotions, like colors, can be expressed at different intensities and can mix with one another to form secondary and tertiary emotions. The respondents were offered options to choose between indicators for rejection (fear, terror, as extreme fear and hate) and indicators of acceptance (indifference, curiosity and affection) in order to underline the two opposite poles of affection. The offered choices were considered to generally cover the potential positive, neutral, and negative emotions. If none of these options matched the respondents' choice, they still had the possibility to simply not answer or to choose the option considered closest to the one they experienced (e.g., choose "affection" instead of "love").

Statistical analyses were carried out using the R Project for Statistical Computing [29]. To test the possible association between cumulated cognitive score and the chosen management actions (resulting from the tolerance levels expressed by subjects) an analysis of deviance (ANODE) was used on a cumulative link mixed model (CLMM). The CLMM included as random effects the locality, gender and age category of respondents, in order to control for the "nuisance" effect produced by these variables. The ANODE is recommended as an appropriate alternative for ANOVA, when the variables are categorical [30]. Unlike ANOVA, the ANODE uses "deviance" instead of sum of squares and a chi-squared test instead of the F-test. The CLMM model was implemented in R using "clmm" function from "ordinal" package [31]. The ANODE from package "RVAideMemoire" [32] (function "Anova") was further used to test the differences among mean CES values of the groups defined by tolerance categories. The significance level was set to 0.05 .

\section{Results}

\subsection{The Human-Bear Interaction}

Out of the 400 interviewees, approximately $20 \%$ reported different types of direct interaction with the bears (Table 2). However, out of these, a rather large percentage of subjects (approximately 
$38 \%$ ) refused to give details on the type of attack (Figure 2). Those reporting interactions in the environment of the subject (indirect-interpersonal mediated interactions) represent approximately $36 \%$ of the total sample, while for those mentioning cases reported by the media (indirect-impersonal mediated interactions), the percentage increased to $84 \%$. Only $10 \%$ (40 respondents out of the total of 400) declared they had no knowledge of any type of interactions.

Table 2. The types of interactions with bears reported (sample size 400; a subject can experience more than one type of interaction).

\begin{tabular}{|c|c|c|c|}
\hline \multirow{2}{*}{ Interaction Type } & \multirow{2}{*}{ Description } & \multicolumn{2}{|c|}{ Cases Reported } \\
\hline & & no. & $\%$ \\
\hline \multirow{7}{*}{$\begin{array}{l}\text { Personal direct } \\
\text { interaction (approx. } \\
20 \% \text { of total sample) }\end{array}$} & Missing description & 30 & 38 \\
\hline & Crops destruction & 14 & 18 \\
\hline & Livestock destruction in shepherd camp & 10 & 13 \\
\hline & Livestock destruction in household & 6 & 7 \\
\hline & Aggression on relatives & 9 & 11 \\
\hline & Aggression on the subject & 10 & 13 \\
\hline & TOTAL & 79 & 100 \\
\hline \multirow{3}{*}{$\begin{array}{l}\text { Personal mediated } \\
\text { interaction (approx. } \\
36 \% \text { of total sample) }\end{array}$} & People suffered & 95 & 66 \\
\hline & People did not suffer & 48 & 34 \\
\hline & TOTAL & 143 & 100 \\
\hline \multirow{4}{*}{$\begin{array}{l}\text { Impersonal mediated } \\
\text { interaction (approx. } \\
84 \% \text { of total sample) }\end{array}$} & People suffered & 235 & 71 \\
\hline & Sometimes yes, sometimes no & 58 & 17 \\
\hline & People did not suffer & 40 & 12 \\
\hline & TOTAL & 333 & 100 \\
\hline \multirow{2}{*}{$\begin{array}{l}\text { Absent }(10 \% \text { of total } \\
\text { sample) }\end{array}$} & No knowledge of interaction & 40 & 100 \\
\hline & TOTAL & 40 & 100 \\
\hline
\end{tabular}

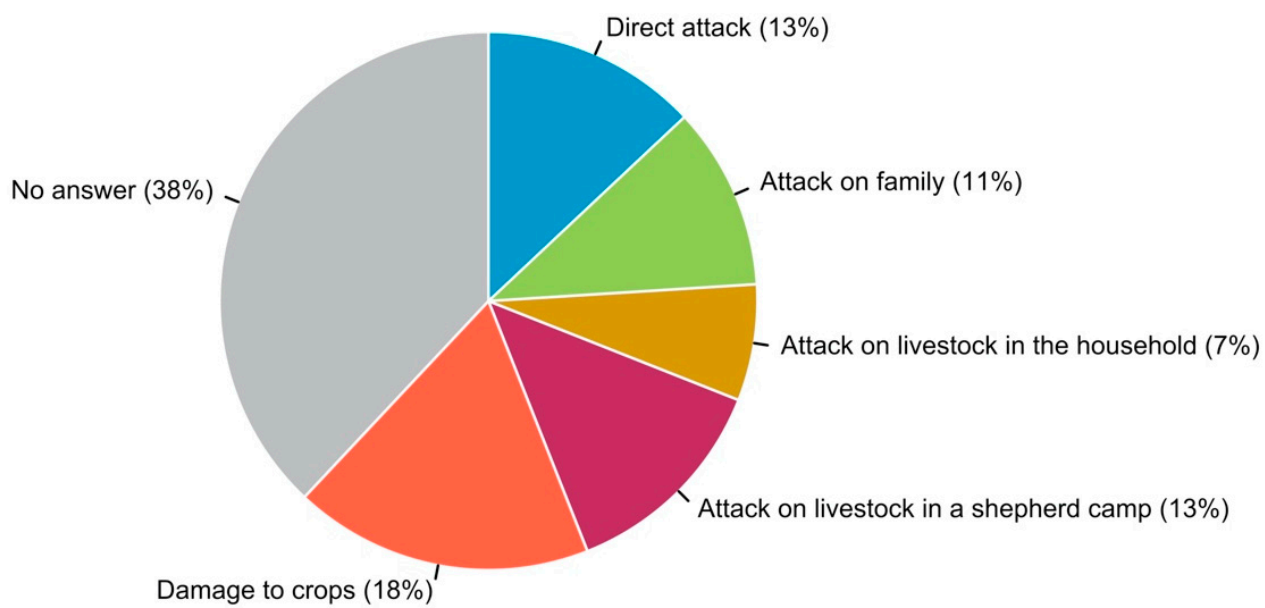

Figure 2. Proportion of the types of direct interactions with bears (sample size 79).

\subsection{The Expressed Tolerance}

When respondents were asked about the measures which should be taken towards aggressive bears (i.e., to express their tolerance/intolerance), most of the respondents (389 out of $400,97.2 \%$ of the sample) chose among the available options provided in the questionnaire. Only very few (11 respondents, $2.8 \%$ of the sample) did not find among these options their choice (whether it was no-action or another type of action or they just did not want to make a choice) and refused to answer. Among those who chose an option, most (46.5\% of the respondents) preferred the isolation intolerance type where the bear must be captured and relocated far away from human settlements (Figure 3). 
The average intolerance type (punishment) represented only $1.3 \%$ of the sample, probably based on the perception that the animal has no capacity to learn from punishment. The fact that respondents from the two categories have not chosen death suggests that they do not seek revenge ("an eye for an eye") but definitely, by expelling the bears to a different area outside of their habitat (i.e., to a different world), show rejection. The most aggressive form of intolerance (i.e., extreme intolerance type-killing) was chosen by 83 respondents ( $20.8 \%$ of the cases). However, the respondents selecting this option were subject to almost all types of experiences (Table 3). Although extreme events would be expected to trigger extreme reactions, only 22 of the 83 extreme intolerance-type responses (proposing "kill" as management action) were linked to direct interactions. In addition, out of these cases, relatively few were linked to direct aggression on subjects or their relatives (6 and 1, respectively). A quite large percentage (40\%: 16 out of 40 respondents) of those who had no knowledge about interactions with the bears (direct, interpersonal, impersonal) chose the extreme measure of killing the animal in the case it has aggressed a human.

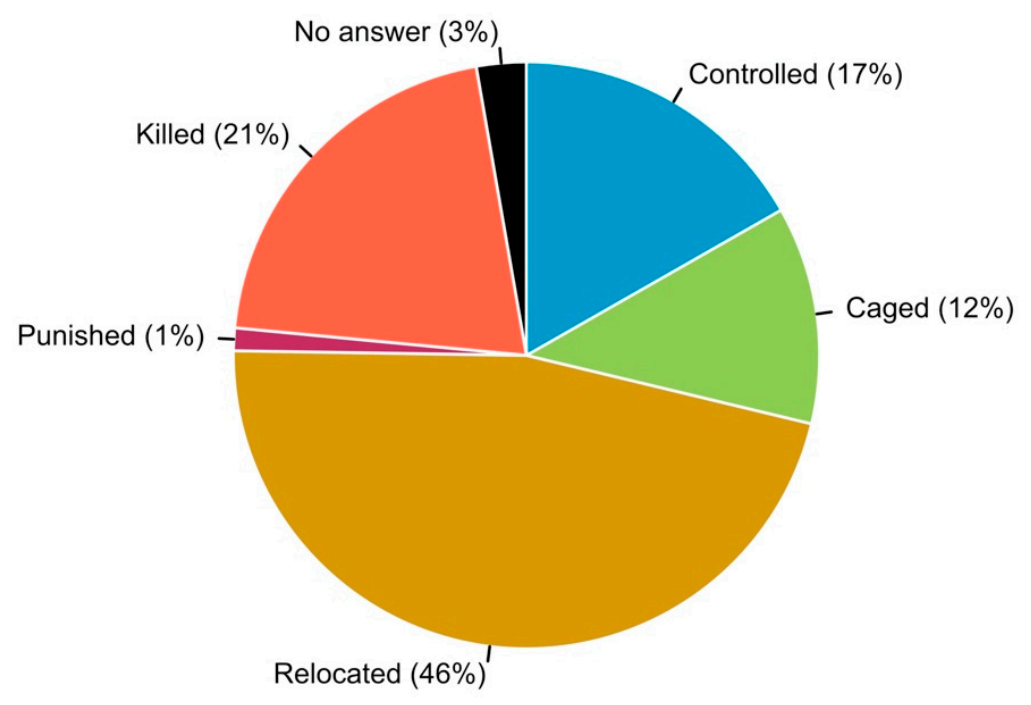

Figure 3. Proportion of management choices where a bear has aggressed humans (sample size 400; killed $=$ extreme intolerance type, punished $=$ average intolerance type, relocated $=$ isolation intolerance type, caged = indifference tolerance type, controlled = generosity tolerance type).

Table 3. The types of interactions which drove the extreme intolerance type (or management option "kill") of the interviewed subjects.

\begin{tabular}{llc}
\hline Type of Interaction & & No. of Cases with “Kill” Option \\
\hline & direct aggression & 6 \\
& aggression on family members & 1 \\
& attack on livestock in the household & 0 \\
Direct interaction & attack on livestock in the shepherd camp & 6 \\
& damage to crops & 4 \\
& no answer & 5 \\
\cline { 2 - 3 } & Total & $\mathbf{2 2}$ \\
\hline \multirow{5}{*}{ Indirect interaction } & interpersonal & 2 \\
& impersonal & 25 \\
& no answer & 18 \\
\cline { 2 - 3 } & Total & 16 \\
\hline Grand Total & & $\mathbf{6 1}$ \\
\hline
\end{tabular}


If we sum up these three forms of intolerance, the total percentage of those perceiving that bears, once they get aggressive, should not belong to the same "world" with humans is raised to $68.6 \%$. The "indifference" and "generosity" tolerance types reached generally low percentages ( $12 \%$ and $16.8 \%$, respectively) in these communities embedded in the bear habitat landscapes.

The results of the ANODE on the CLMM showed no significant differences $(p=0.470)$ in the cumulated cognitive score among the different actions proposed by respondents in the case of a bear aggression on humans (regardless of location, gender, and age class) and therefore, does not support the initial hypothesis of the study which implies that when the experience intensity gets higher, the chance for extreme intolerance also becomes higher. Also, the similar distribution of CES (Figure 4) across the 5 different categories of tolerance (i.e., management options) supports this result.

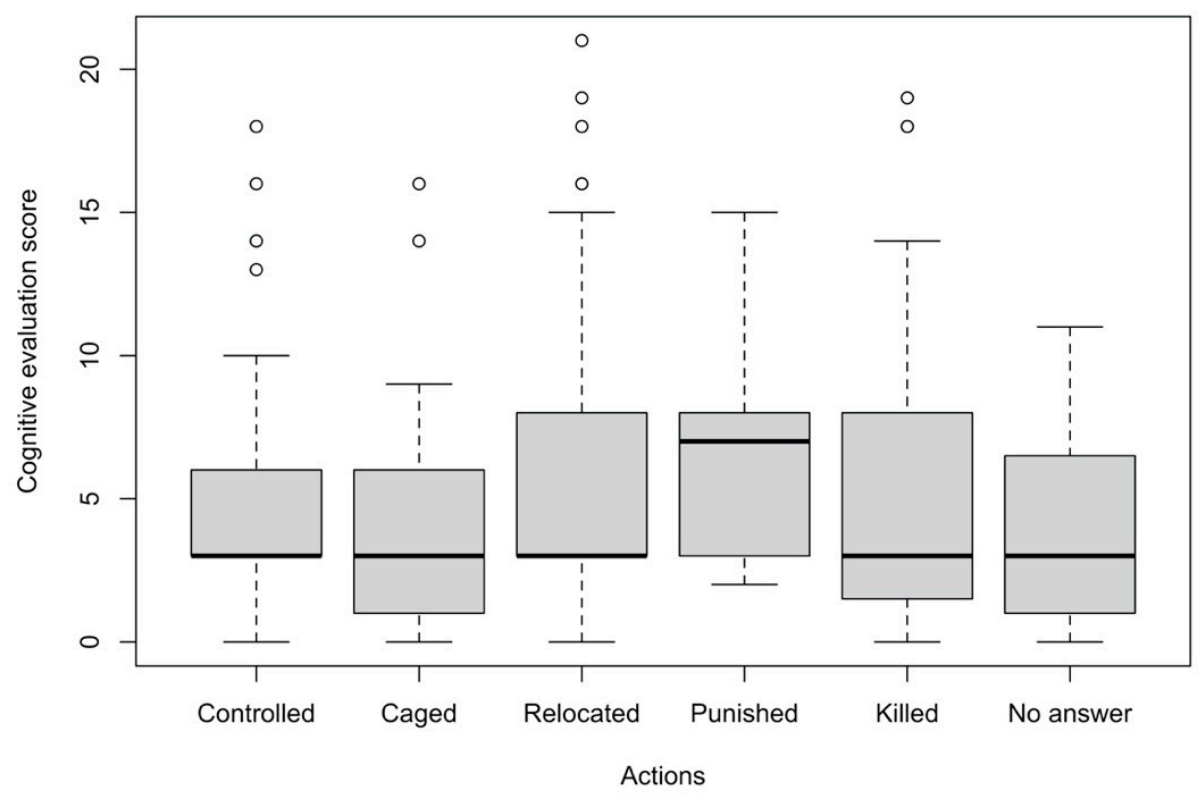

Figure 4. Distribution of cognitive evaluation score (CES) on actions derived from the "tolerance level" classes. Note: thick horizontal lines represent the median; boxes are mid quartile ranges; whiskers extend to the upper and lower quartile limits; outliers are represented as individual points (sample size 400).

\subsection{The Experienced Emotions}

In terms of the perceived emotional experience, despite the relatively frequent interactions with these powerful carnivores in the studied areas, very few respondents have chosen "hate" as an experienced emotion. However, the prevalent experienced emotions in the case of encountering a bear outside of the human settlements (even if it is not aggressive to the subject) were fear $(51.75 \%$ of respondents) and terror (19.50\% of respondents) (Figure 5). Therefore, the negative emotions expressed by most of the respondents $(71.25 \%)$ show that inhabitants of local communities, in general, perceive the animal as a threat not only inside their settlements but also outside, in the areas where their habitats overlap. Those expressing indifference, affection, and curiosity represent $8.00 \%, 8.50 \%$, and $10.75 \%$ of the total sample, respectively. Only $1 \%$ of respondents did not choose any of the offered options. 


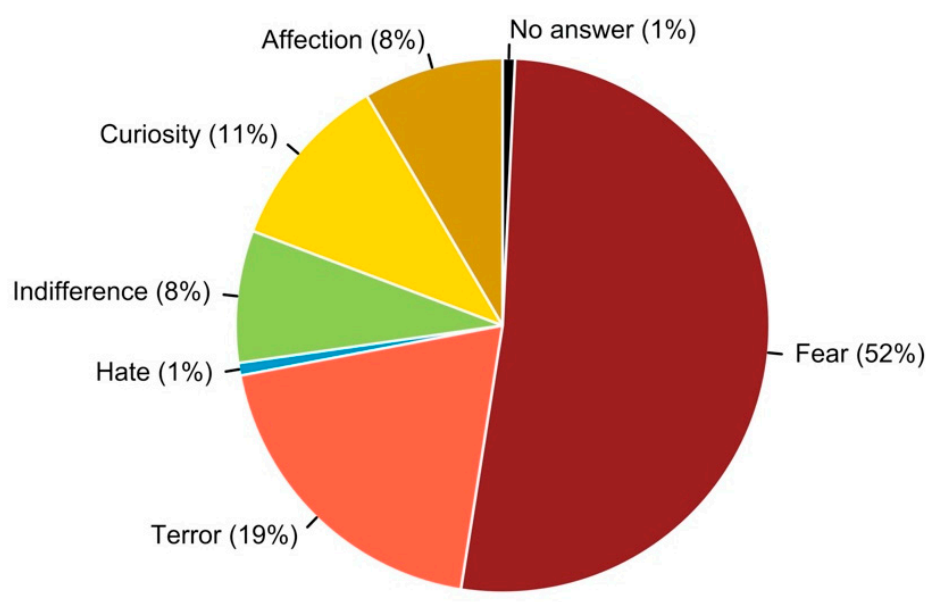

Figure 5. Proportion of declared experienced emotions (sample size 400).

\section{Discussion}

\subsection{Interaction with Bears: Mutualism or Competition}

As it was previously shown elsewhere, people from outside the ecosystem (having less direct experiences with carnivores and incurring no loss or damage) tend to have a more positive attitude towards dangerous wildlife, while those that are part of the ecosystem (subject to interactions, like the ones in this study) have a more negative attitude $[7,8]$. The more positive attitude was considered to be a result of mutualism [4]. However, mutualism in ecology involves not only living in the same place but also a relationship with beneficial effects for both players [33]. In nature, such a relationship is not possible between species which utilize the same resources, in such cases the relationship being fierce competition instead $[18,34]$. When one species has better competitive abilities over the other, such a fight for vital resources (i.e., struggle for existence), results mostly in the domination of one species over the other (the latter eventually can be even eliminated from the ecosystem) [18]. Even in the case of niche differentiation, the result is not a truly and beneficial coexistence on long-term in the same place and in the same time (i.e., mutualism) but rather "living in separate worlds", as expected by the respondents from this study.

Compared to other studies carried out in a relatively in similar context $[35,36]$ this work took into account very different choices in terms of emotions towards bears (both positive and negative, covering the two opposite poles of affection). The very low proportion ( $8 \%$ ) of those showing affection even in the case of non-aggressive bears shows that local dwellers from landscapes with bears do not perceive the relationship with these animals as a mutually beneficial one (mutualism). Conversely, the prevalent emotions of communities from this study classify this relationship more likely as competition. Moreover, the general rejection attitude (i.e., the need for living in separate worlds) detected in this study and also suggested by the people's opposition to the return/reintroduction of carnivores in countries where they have been eliminated in the past [37], is a clear sign of exclusion. Such exclusion is an effect of direct competition, an interaction which leads to dominance of one player or coexistence through mutual avoidance but definitely not to mutualism. Therefore, managing the situation in a competition context seems more realistic and efficient than relying upon a mutualistic relationship which is unlikely to be reached in these environments. This confirms the findings of others [4] that people with subsistence and safety needs will express domination in terms of wildlife value orientation and not mutualism.

\subsection{The Importance of Intangible Costs}

Despite the fact that the experience of interaction with the animal has been shown to be important $[17,38]$, many studies on human dimensions of wildlife have not included this variable in the analysis [38]. The detailed but also cumulative experience with bears used in this research 
helped better understand the relationship between such experience (direct or indirect) and tolerance. The general intolerance towards aggressive bears and the prevalent emotion of fear (and terror) even towards a non-aggressive bear met outside of the human settlements found in this study, show that in such environments people are prone to negative attitudes towards bears getting close to them. Moreover, people in the communities addressed by this research, sharing the landscapes with bears, generally express intolerance and will also tend to support different forms of exclusion of bears ("living in separate worlds"), including extreme management solutions (e.g., killing the bear) regardless of the intensity level of interactions with these powerful carnivores. This should not be too surprising as we expect dwellers living in an environment where chances of conflict not only exist but are generally high, to be more aware of the potential threat/danger. Moreover, a large share of the respondents in this study who showed extreme intolerance (chose "kill" as an option for aggressive bears) were people experiencing no direct interaction with bears. These results support the conclusions of previous studies [6,17] that intangible costs (i.e., the indirect costs like psychological costs of fear, danger, or risk) associated with carnivores are much more important than direct tangible costs (e.g., damage) in driving negative attitudes towards these species. Therefore, avoiding high intangible costs (which bring rejection and not tolerance) in the communities sharing habitat with bears seems to be the key for conservation. However, this goal is highly unlikely to be reached under the present strict protection regime imposed on this species.

\subsection{The Coexistence Compromise}

Large, viable, and connected bear populations, like the one existing for a long time in Romania, require very large landscapes with favorable habitats. Such extended areas, in the European context, embed numerous local communities, making coexistence of the two players not an option but a mandatory condition for successful conservation. However, the required very large habitat is and will remain favorable for bears only if humans will show tolerance to them (i.e., will accept sharing the landscapes).

The results of our study show that people living in environments with frequent interactions with the animals (even indirect) were less forgiving and generally showed negative attitudes (including extreme intolerance) confirming findings of previous research $[7,8]$. However, in this case, gender and age class did not play an important role in the expressed tolerance, as found elsewhere [35,36,38], showing that such small communities are rather homogenous in this respect. Moreover, as shown in other studies, such local communities might not accept the conservation costs imposed by strict protection but rather engage in hidden actions like illegal killing for safety reasons [39] or simply as a form of protesting against conservation $[6,40]$, which is perceived to be discrimination, rather than sharing the conservation efforts.

Therefore, the coexistence of species in competition (like bears and humans) must be a middle ground ("a compromise" [41]) of neither the complete domination of humans (extermination of the bears), nor the complete freedom of the animal (i.e., the chance, offered by the full protection status of the species, to freely use the resources) being viable solutions, as both would lead in the end to the extinction of bears. A balance between the competitive abilities of both players is required to ensure a stable cohabitation (the "strong coexistence" [18]). Such balance cannot be achieved by simply limiting only the humans' competitive abilities (through restrictions imposed by regulations and control agencies) but mainly by finding ways to ensure the acceptance of those who share the ecosystem with wild animals. However, as mentioned above, acceptance is conditioned by the level of psychological perception of fear, danger, or risk (the intangible costs) associated with the bears. Low levels of such intangible costs would ensure the perception of safety in the local communities (the feeling of "living in separate worlds", as shown in this study) and would generally avoid the negative attitudes which may put the bear conservation at risk. This can be ensured only if carnivores perceive humans as deadly enemies and, thus, will generally avoid them and their property (ensuring therefore a good niche differentiation, one of the main drivers for a strong coexistence [18]). Avoidance (in the context of the two species seeking the same resources) requires that the actors experience fear and 
not trust and tolerance (which brings them close to each other). As human fear is likely to drive the extinction of bears, the bears' fear seems to be more appropriate to ensure the existence of both players. Making bears avoid humans means controlling their competitive abilities to a certain extent and, thus, reaching the middle ground where neither one of the two competing actors has complete power over the other.

The current passive management does not seem to ensure such control as it only tries to repair the damage (restore the loss) after it is produced (and the conflict has already occurred). The relocation of problem bears, the most commonly used method, would ensure the "living in separate worlds" required by most of the respondents in this study is only for the short term, as relocated bears usually either come back to their original place or reach other close human settlements for rich and easily accessible food sources (therefore relocating the problem). The use of bear-safe garbage bins and controlled waste disposal have reduced bear presence but not eliminated it; in some cases, animals entering even farther inside towns in search for food. Feeding animals inside the forest, far from communities, as a "pull out/keep away" method, especially when combined with wildlife watching, could rather worsen the relationship in the long-term as animals get more used to human presence and associate humans with a constant food source [42], making them even more attracted to human settlements. Electric fences cannot solve the problem on large scale (taking into account the very large number of ownerships and their generally small size) and, if implemented on a large scale, could even have a negative effect by fragmenting the habitat of bears and many other species.

None of these passive methods keep bears away from humans in terms of making them perceive the competition context and, therefore, control their competitive abilities. Instead, they would stimulate bears to try finding a way around to access the rich food sources provided by human settlements and crops. The goal of making bears wary of humans cannot be attained through strict protection but requires creating or re-creating the "landscape of fear" [14-16] for bears. The active management (sustainable hunting) practiced in the past seems to have been efficient not only in maintaining and even increasing bear populations $[13,36]$ but also in making bears avoid humans, as shown in other parts of Europe where vigorous bear populations are still present [43,44]. Even if this kind of coexistence would make bears "look over their shoulders" (be vigilant) and not give them the chance of fully expressing their role of apex predators [41], it would definitely benefit the relationship as the avoidance of humans would bring acceptance for bears. This, in turn, would help avoid bear elimination and the creation of artificial ecosystems (where humans will not be able to replace the ecological role of carnivores in the ecosystems [45]) and, thus, would be a middle ground compared to strict protection. Moreover, a full apex predator role attributed to bears might be questionable in landscapes where humans and bears have coexisted and competed for ages. If coexistence cannot be ensured in the context of competition, conservation across large landscapes (i.e., the key condition for the existence of large, viable, connected populations) shared by bears and humans, would also fail.

\section{Conclusions}

When the conservation of carnivores requires large and connected landscapes that embed many human communities, decision making must be done at the appropriate level, namely, the local communities representing the human population directly involved in the interaction (i.e., being part of the ecosystem). Here we argue that, based on the local realities, policy makers should develop context-specific management strategies which will bring local support for wildlife conservation [36] in comparison with general strategies (which seem to bring the opposite effect). This becomes even more important if those living outside of the bear inhabited landscapes express more positive attitudes, as found in other studies $[7,8,38]$. Such segregation would raise the potential for conflict over the conservation strategies at a country level and the attitudes of general public could also mask the particular needs of small local communities (the real part of the ecosystems at stake). The generally negative feelings of the local communities towards bears in this study underline the need for "living in separate worlds" (i.e., the need for safety) as a key for coexistence of these two competing species. 
A compromise (i.e., no reduction in carnivores' habitats to physically separate the worlds) can be attained in the same shared landscapes only if bears avoid humans (i.e., a shifting landscape habitat where bears retreat when humans are around and come back after they leave). The present strict protection regime is not likely to ensure such avoidance but instead to favor conflicts, as already shown in Slovenia [35]. A low level of conflict needs a different strategy; one that would not only keep the bear population density under control but mostly ensure mutual avoidance (the key for general acceptance of bears by humans and for ensuring a true coexistence).

Supplementary Materials: S1-Sample questionnaire and S2-Sample structure are available online at http: //www.mdpi.com/2071-1050/11/24/7167/s1.

Author Contributions: Conceptualization, P.T.S.; methodology, P.T.S., M.C.B. and S.V.U.; formal analysis, P.T.S. and I.D.; writing —original draft preparation, P.T.S.; writing-review and editing, I.D., M.C.B. and S..V.U. All authors have read and agreed to the published version of the manuscript.

Acknowledgments: The data for the study was collected within the framework of the Project LIFE EX-TRA-“Improving the conditions for large carnivore conservation: a transfer of best practices" (LIFE07/NAT/TT/000502). The authors would like to thank to the volunteers who collected the data in the field. Help provided by the anonymous reviewers for improving the manuscript is greatly appreciated.

Conflicts of Interest: The authors declare no conflict of interest.

\section{References}

1. Fischer, J.; Lindenmayer, D.B. Landscape modification and habitat fragmentation: A synthesis. Glob. Ecol. Biogeogr. 2007, 16, 265-280. [CrossRef]

2. O'Hara, K.L. Stand structure and growing space efficiency following thinning in an even-aged Douglas-fir stand. Can. J. For. Res. 1988, 18, 859-866. [CrossRef]

3. Carter, N.H.; Linnell, J.D.C. Co-Adaptation Is Key to Coexisting with Large Carnivores. Trends Ecol. Evol. 2016, 31, 575-578. [CrossRef] [PubMed]

4. Teel, T.L.; Manfredo, M.J.; Jensen, F.S.; Buijs, A.E.; Fischer, A.; Riepe, C.; Arlinghaus, R.; Jacobs, M.H. Understanding the cognitive basis for human-wildlife relationships as a key to successful protected-area management. Int. J. Sociol. 2010, 40, 104-123. [CrossRef]

5. Vaske, J.J.; Roemer, J.M.; Taylor, J.G. Situational and emotional influences on the acceptability of wolf management actions in the Greater Yellowstone Ecosystem. Wildl. Soc. Bull. 2013, 37, 122-128. [CrossRef]

6. Pooley, S.; Barua, M.; Beinart, W.; Dickman, A.; Holmes, G.; Lorimer, J.; Loveridge, A.J.; Macdonald, D.W.; Marvin, G.; Redpath, S.; et al. An interdisciplinary review of current and future approaches to improving human-predator relations. Conserv. Biol. 2017, 31, 513-523. [CrossRef]

7. Williams, C.K.; Ericsson, G.; Heberlein, T.A. A quantitative summary of attitudes toward wolves and their reintroduction (1972-2000). Wildl. Soc. Bull. 2002, 30, 575-584.

8. Eriksson, M. Rurality and collective attitude effects on wolf policy. Sustainability 2016, 8, 711. [CrossRef]

9. Gross, L. No place for predators? PLoS Biol. 2008, 6, 199-204. [CrossRef]

10. Frank, L.G.; Woodroffe, R. Behaviour of carnivores in controlled and exploited populations. In Carnivore Conservation; Gittleman, J.L., Funk, S.M., MacDonald, D.W., Wayne, R.K., Eds.; Cambridge University Press: Cambridge, UK, 2001.

11. Mattson, D.J. Human Impacts on Bear Habitat Use. Bears Their Biol. Manag. 1990, 8, 33-56. [CrossRef]

12. Woodroffe, R.; Ginsberg, J.R. Edge effects and the extinction of populations inside protected areas. Science 1998, 280, 2126-2128. [CrossRef] [PubMed]

13. Chapron, G.; Kaczensky, P.; Linnell, J.D.C.; von Arx, M.; Huber, D.; Andrén, H.; López-Bao, J.V.; Adamec, M.; Álvares, F.; Anders, O.; et al. Recovery of large carnivores in Europe's modern human-dominated landscapes. Science 2014, 346, 1517-1519. [CrossRef] [PubMed]

14. Laundré, J.W.; Hernández, L.; Altendorf, K.B. Wolves, elk, and bison: Reestablishing the "landscape of fear" in Yellowstone National Park, U.S.A. Can. J. Zool. 2001, 79, 1401-1409. [CrossRef]

15. Lodberg-Holm, H.K.; Gelink, H.W.; Hertel, A.G.; Swenson, J.E.; Domevscik, M.; Steyaert, S.M.J.G. A human-induced landscape of fear influences foraging behavior of brown bears. Basic Appl. Ecol. 2019, 35, 18-27. [CrossRef] 
16. Støen, O.-G.; Ordiz, A.; Evans, A.L.; Laske, T.G.; Kindberg, J.; Fröbert, O.; Swenson, J.E.; Arnemo, J.M. Physiological evidence for a human-induced landscape of fear in brown bears (Ursus arctos). Physiol. Behav. 2015, 152, 244-248. [CrossRef]

17. Kansky, R.; Knight, A. Key factors driving attitudes towards large mammals in conflict with humans. Biol. Conserv. 2014, 179, 93-105. [CrossRef]

18. Chapron, G.; López-Bao, J.V. Coexistence with Large Carnivores Informed by Community Ecology. Trends Ecol. Evol. 2016, 31, 578-580. [CrossRef]

19. Inventarul Forestier National. Available online: http://www.roifn.ro (accessed on 5 July 2019).

20. Ordinul nr. 625/2018 privind aprobarea Planului naţional de acţiune pentru conservarea populaţiei de urs brun din România. Law 625/2018, 2018. Available online: https://lege5.ro/Gratuit/gi4domzvgy4a/ordinul-nr625-2018-privind-aprobarea-planului-national-de-actiune-pentru-conservarea-populatiei-de-urs-brundin-romania (accessed on 12 December 2019).

21. Decretul nr. 76/1953 cu privire la economia vânatului şi pescuitului în apele de munte. Decree 76/1953, 1953. Available online: https://lege5.ro/Gratuit/heydemrtgy/decretul-nr-76-1953-cu-privire-la-economiavanatului-si-pescuitului-in-apele-de-munte (accessed on 12 December 2019).

22. Legea nr. 26/1976 privind economia vînatului si vînătoarea. Law 26/1976, 1976. Available online: https: //lege5.ro/Gratuit/he2tknru/legea-nr-26-1976-privind-economia-vinatului-si-vinatoarea (accessed on 12 December 2019).

23. Legea fondului cinegetic şi a protecţiei vânatului nr. 103/1996. Law 103/1996, 1996. Available online: https://lege5.ro/Gratuit/ge3demzq/legea-fondului-cinegetic-si-a-protectiei-vanatului-nr-103-1996 (accessed on 12 December 2019).

24. Legea vânătorii şi a protecţiei fondului cinegetic nr. 407/2006. Law 407/2006, 2006. Available online: https://lege5.ro/Gratuit/geydamjsgq/legea-vanatorii-si-a-protectiei-fondului-cinegetic-nr-407-2006 (accessed on 12 December 2019).

25. Ordonanţa de urgenţă nr. 57/2007 privind regimul ariilor naturale protejate, conservarea habitatelor naturale, a florei şi faunei sălbatice. Government Emergency Ordinance 57/2007, 2007. Available online: https:/lege5.ro/Gratuit/geydqobuge/ordonanta-de-urgenta-nr-57-2007-privind-regimul-ariilor-naturaleprotejate-conservarea-habitatelor-naturale-a-florei-si-faunei-salbatice (accessed on 12 December 2019).

26. Merriam Webster. Available online: https://www.merriam-webster.com (accessed on 10 July 2019).

27. Schachter, S.; Singer, J. Cognitive, social, and physiological determinants of emotional state. Psychol. Rev. 1962, 69, 379-399. [CrossRef]

28. Plutchik, R. Emotions and Life: Perspectives from Psychology, Biology, and Evolution; American Psychological Association: Washington, DC, USA, 2003.

29. R Core Team. R: A language and Environment for Statistical Computing; R Foundation for Statistical Computing: Vienna, Austria, 2018.

30. Christensen, H.R.B. Analysis of ordinal data with cumulative link models-estimation with the R-package ordinal. Available online: https:/mran.microsoft.com/snapshot/2015-03-04/web/packages/ordinal/vignettes/ clm_intro.pdf (accessed on 25 November 2019).

31. Christensen, H.R.B. Package "ordinal": Regression Models for Ordinal Data. Available online: https: //cran.r-project.org/web/packages/ordinal/ordinal.pdf (accessed on 1 December 2019).

32. Hervé, M. Package "RVAideMemoire": Testing and Plotting Procedures for Biostatistics 2019. Available online: https://rdrr.io/cran/RVAideMemoire/ (accessed on 12 December 2019).

33. West, S.A.; Griffin, A.S.; Gardner, A. Social semantics: Altruism, cooperation, mutualism, strong reciprocity and group selection. J. Evol. Biol. 2007, 20, 415-432. [CrossRef]

34. Begon, M.; Townsend, C.R.; Harper, J.L. Ecology: From Individuals to Ecosystems, 4th ed.; Wiley-Blackwell: Hoboken, NJ, USA, 2006.

35. Kaczensky, P.; Blazic, M.; Gossow, H. Public attitudes towards brown bears (Ursus arctos) in Slovenia. Biol. Conserv. 2004, 118, 661-674. [CrossRef]

36. Majić, A.; Marino Taussig de Bodonia, A.; Huber, Đ.; Bunnefeld, N. Dynamics of public attitudes toward bears and the role of bear hunting in Croatia. Biol. Conserv. 2011, 144, 3018-3027. [CrossRef]

37. Enserink, M.; Vogel, G. Wildlife conservation. The carnivore comeback. Science 2006, 314, 746-749. [CrossRef] [PubMed] 
38. Dressel, S.; Sandström, C.; Ericsson, G. A meta-analysis of studies on attitudes toward bears and wolves across Europe 1976-2012. Conserv. Biol. 2015, 29, 565-574. [CrossRef] [PubMed]

39. Holmes, G. Protection, politics and protest: Understanding resistance to conservation. Conserv. Soc. 2007, 5, 184-201.

40. von Essen, E.; Hansen, H.P.; Nordström Källström, H.; Peterson, M.N.; Peterson, T.R. The radicalisation of rural resistance: How hunting counterpublics in the Nordic countries contribute to illegal hunting. J. Rural Stud. 2015, 39, 199-209. [CrossRef]

41. Ordiz, A.; Bischof, R.; Swenson, J.E. Saving large carnivores, but losing the apex predator? Biol. Conserv. 2013, 168, 128-133. [CrossRef]

42. Penteriani, V.; López-Bao, J.V.; Bettega, C.; Dalerum, F.; del Mar Delgado, M.; Jerina, K.; Kojola, I.; Krofel, M.; Ordiz, A. Consequences of brown bear viewing tourism: A review. Biol. Conserv. 2017, 206, 169-180. [CrossRef]

43. Swenson, J.E. Does hunting affect the behavior of brown bears in Eurasia? Ursus 1999, 11, 157-162.

44. Treves, A.; Karanth, K.U. Human-carnivore conflict and perspectives on carnivore management worldwide. Conserv. Biol. 2003, 17, 1491-1499. [CrossRef]

45. Kuijper, D.P.J. Lack of natural control mechanisms increases wildlife-forestry conflict in managed temperate European forest systems. Eur. J. For. Res. 2011, 130, 895-909. [CrossRef]

(C) 2019 by the authors. Licensee MDPI, Basel, Switzerland. This article is an open access article distributed under the terms and conditions of the Creative Commons Attribution (CC BY) license (http://creativecommons.org/licenses/by/4.0/). 